\title{
Chapter 15 \\ Evaluating Socio-economic and Environmental Sustainability of the Sheep Farming Activity in Greece: A Whole-Farm Mathematical Programming Approach
}

\author{
Alexandra Sintori, Konstantinos Tsiboukas, and George Zervas
}

\begin{abstract}
Ruminant livestock farming is an important agricultural activity, mainly located in less favoured areas. Furthermore, ruminants have been identified as a significant source of GHG emissions. In this study, a whole-farm optimisation model is used to assess the socio-economic and environmental performance of the dairy sheep farming activity in Greece. The analysis is undertaken in two sheep farms that represent the extensive and the semi-intensive farming systems. Gross margin and labour are regarded as socio-economic indicators and GHG emissions as environmental indicators. The issue of the marginal abatement cost is also addressed. The results indicate that the semi-intensive system yields a higher gross margin/ewe (179 €) than the extensive system (117 €) and requires less labour. The extensive system causes higher emissions $/ \mathrm{kg}$ of milk than the semi-intensive system (5.45 and $2.99 \mathrm{~kg}$ of $\mathrm{CO}_{2}$ equivalents, respectively). In both production systems, abatement is achieved primarily via reduction of the flock size and switch to cash crops. However, the marginal abatement cost is much higher in the case of the semi-intensive farms, due to their high productivity.
\end{abstract}

Keywords Dairy sheep farming • Mathematical programming $\bullet$ GHG emissions - Socio-economic performance $\cdot$ Environmental performance $\bullet$ Abatement cost

\footnotetext{
A. Sintori $(\varangle) \cdot K$. Tsiboukas

Department of Agricultural Economics and Rural Development,

Agricultural University of Athens (AUA), Iera Odos 75, 11855 Athens, Greece

e-mail: al_sintori@yahoo.gr; tsiboukas@aua.gr

G. Zervas

Department of Nutritional Physiology and Feeding Faculty of Animal Science

and Aquaculture, Agricultural University of Athens (AUA),

Iera Odos 75, 11855, Athens, Greece

e-mail: gzervas@aua.gr
} 


\subsection{Introduction}

Ruminant livestock farming, especially sheep farming, is an important agricultural activity in Greece, since it is mainly located in less favoured areas of the country and utilises less fertile and abundant pastureland. The activity yields income for thousands of farms mainly located in marginal areas, where few alternative economic activities can develop. These farms are dairy farms, since they aim primarily at the production of sheep milk that is responsible for over $60 \%$ of their gross revenue and secondarily at the production of meat (Kitsopanides 2006). It is estimated that almost $40 \%$ of the total milk produced in Greece is sheep milk. Furthermore, the activity contributes highly in regional development and helps maintain the population in the depressed areas, where it is located. Therefore, the preservation of the activity and the income it yields is important not only for farmers but also for policymakers.

The prevailing sheep farming system in the country is the extensive system, in which the feed requirements of the flock are met mainly through grazing. Extensive breeding farms are characterised by low invested capital with low-productivity flocks, consisting mainly of native breeds (HMRDF 2007 ${ }^{1}$ ). More modern and intensive farms that are also present have a higher invested capital and aim to increase their productivity through supplementary feeding, mainly from on-produced cereals and forage. These two main production systems identified in the Greek sheep farming activity have different characteristics and therefore different economic and environmental performance.

The matter of greenhouse gas (GHG) emissions has recently received extra attention in light of the Kyoto protocol and Europe's commitment to reduce emissions. Agriculture has been identified as a significant source of GHGs, and farmers are urged to adopt not only economically viable but also environmentally sound farming practices. GHG emissions are particularly high in the case of ruminant livestock farming because of methane production through enteric fermentation (Pitesky et al. 2009). The issue of GHG emissions in livestock farms has been addressed in a number of studies that focus mainly in dairy cow and cattle farms (Olesen et al. 2006; Weiske et al. 2006; Veysset et al. 2010). On the other hand, studies that focus on the emission of GHGs from sheep farms refer mainly to meat and wool production farms that have different technicoeconomic characteristics than dairy sheep farms (e.g. Benoit and Laignel 2008; Petersen et al. 2009).

This study aims primarily at the evaluation of the socio-economic and environmental performance of the dairy sheep farming activity in Greece, through the use of a whole-farm optimisation model. In this model, environmental performance is measured through the estimation of the net GHG emissions of the sheep farms. The issue of the GHG abatement cost is also addressed, since mitigation leads to loss of

\footnotetext{
${ }^{1}$ Hellenic Ministry of Rural Development and Food.
} 
income. The analysis is undertaken in two farms representing the extensive and the semi-intensive farming systems that are commonly found in the country. In the next section, the mathematical model used in the analysis is described in more detail. The characteristics of the extensive and the semi-intensive farms are also presented. The third section contains the results of the analysis, and the final section includes some concluding remarks.

\subsection{Data and Methods}

Mathematical programming models are commonly used in agricultural studies (e.g. Alford et al. 2004; Veysset et al. 2005; Crosson et al. 2006). They yield the optimal amongst all feasible farm plans, taking into account technical and agronomic constraints of the farms. In the case of livestock and crop-livestock farms, the complexity of the farm operation and the substitution possibilities between alternative activities require the use of a model that can capture all the interrelationships of these activities. The multiple sources of GHGs in crop-livestock farms present another reason for a mathematical programming model to be used (De Cara and Jayet 2000). Thus, a number of studies have utilised mathematical programming models to assess GHGs from various sources and identify cost-effective mitigation strategies (e.g. Smith and Upadhyay 2005; Breen and Donnellan 2009; Petersen et al. 2009).

Therefore, a whole-farm, mathematical programming model is considered an appropriate tool for the estimation of the socio-economic and environmental performance of livestock farms. The model used in this analysis incorporates all livestock and crop activities of sheep farms. The characteristics of the farm model are described in more detail in the following paragraphs. The data used in the analysis is also presented in this section.

The first step of our methodology is to use this mathematical model to obtain the optimal farm plan of each of the sheep farms. This optimal farm plan is derived through gross margin maximisation that is assumed to be the objective of the farmers and is used to measure the economic performance of the farms. Labour inputs in this optimal farm plan are considered as an indicator of the social performance of the farm, and net GHG emissions are regarded as an environmental performance indicator. The second step of our methodology is to estimate the optimal farm plan across increasing levels of abatement and assess impact on gross margin and labour. Following a number of studies (e.g. De Cara and Jayet 2000; Smith and Upadhyay 2005), this is achieved by inserting an additional constraint in the model. Specifically, if $e_{0}$ is the original level of net emissions, at the optimal farm plan, and $\alpha$ is the level of abatement $(\alpha<1)$, then a new constraint is inserted in the model not allowing the net farm emissions to be more than $(1-\alpha) e_{0}$. The shadow price of net emissions is also estimated because it indicates the GHG marginal abatement cost for each farm (De Cara and Jayet 2000; Smith and Upadhyay 2005). 


\subsection{Model Specification}

The crop-livestock model used in this analysis maximises total gross margin under the technicoeconomic constraints of the sheep farms and yields the optimal farm plan. For this purpose, it utilises detailed farm-level data on all crop and livestock activities of the farms. The decision variables and the constraints of the model are presented in the next paragraphs. The GHG emission sources that have been taken into account in this analysis are also presented in detail in this section as indicators of the environmental performance of the sheep farms.

\subsubsection{Crop and Livestock Activities}

Crop activities of the sheep farms involve mainly forage and cereal production for livestock feeding. In the model, farmers can produce cereals and forage either for consumption in the farm or for sale, according to what maximises their gross margin. The two farms used in this analysis produce only alfalfa and maize, which are the main crop activities of the sheep farms of the area where the analysis is undertaken.

Two livestock activities are incorporated in the model, according to the time of sale of the lambs. In the first one, lambs are sold after weaning (approximately 42 days after lambing) and the ewes are then milked. The second activity involves the rearing of the lambs for 3 months prior to their sale. In this second alternative, the live weight of the lambs sold is higher, but the price per kilogram is lower. Also, the milk yield is much lower, since lambs are allowed to wean for a longer period of time. The produced fodder is used for the feeding of the livestock. In the model, there is also a set of variables to approximate monthly distribution of the produced feed. Additionally, monthly consumption of purchased maize and alfalfa presents another set of the model variables. Also, the model includes decision variables that reflect the use of pastureland and the monthly consumption of grass. The final set of variables incorporated in the model involves the monthly labour inputs (family and hired labour inputs in crop and livestock activities).

\subsubsection{Feed Requirements}

The main component of the model ensures that the monthly feed requirements of the flock are balanced. Minimum intake of dry matter, net energy of lactation, digestible nitrogen and fibrous matter is ensured through monthly constraints. The feed requirements of the flock are estimated according to Zervas et al. (2000). For the productive ewes, these feed requirements include requirements for maintenance, pregnancy and lactation. For the rams, the requirements refer to their maintenance, 
while for the replacement animals, the feed requirements are estimated every month taking into account the live-weight gain. The weight gain is also taken into account in the case of the lambs, for which feed requirements are estimated for the period that they remain in the farm minus the feed requirements that are satisfied from milk. On-produced feed crops, external feed inputs and available pastureland are used for the balance of the feed requirements of the flock. The nutritional value per kilogram of maize, alfalfa and grass is taken from Kalaisakis (1965) and Zervas et al. (2000).

\subsubsection{Labour and Land Constraints}

A second component of the model ensures that monthly labour requirements of all production activities are balanced mainly with the family labour inputs. Additional hired labour can be used if necessary in both livestock and crop activities. Labour requirements differ between farms according to the specific crop and livestock activities, management practices, type of machinery used and specific land characteristics. Land availability constraints are also incorporated in the model. They refer to the availability of irrigated land, used for alfalfa and maize production; availability of pastureland; and total farmland.

\subsubsection{GHG Emissions}

An extra component has been added in this model that refers to the GHG emissions. The main GHG emissions, from livestock farms, are methane $\left(\mathrm{CH}_{4}\right)$ from enteric fermentation and excreta and nitrous oxide $\left(\mathrm{N}_{2} \mathrm{O}\right)$ from excreta. In addition, in a crop-livestock farm, nitrous oxide $\left(\mathrm{N}_{2} \mathrm{O}\right)$ emissions from fertiliser use should also be accounted for (see, e.g. Schils et al. 2007; Petersen et al. 2009; Veysset et al. 2010). Carbon dioxide $\left(\mathrm{CO}_{2}\right)$ emissions from energy consumption pose an additional source of GHGs. In our analysis, all the potential sources of GHGs have been taken into account when total emissions are estimated. ${ }^{2}$

Methane production from enteric fermentation is the most important source of GHGs in livestock farms, and it is associated with the feeding practices of each farm. Farmers choose to feed their flock with on-produced feed and purchased feed taking into account the cost and the nutritional value of each feedstuff and the feed requirements of the flock. The ration used in this analysis is not fixed, but

\footnotetext{
${ }^{2} \mathrm{CH}_{4}$ and $\mathrm{N}_{2} \mathrm{O}$ have been converted to $\mathrm{CO}_{2}$ equivalents using the following conversion factors: $1 \mathrm{~kg}$ of $\mathrm{CH}_{4}=25$ and $1 \mathrm{~kg}$ of $\mathrm{N}_{2} \mathrm{O}=298$ (IPCC 2006).
} 
it is optimised (see also Petersen et al. 2009). Following the work of De Cara and Jayet (2000), methane emissions are predicted for each feedstuff according to the following equation:

$$
\mathrm{E}-\mathrm{CH}_{4} / \mathrm{EB}=-1.73+13.91 \mathrm{dE}
$$

where $\mathrm{E}-\mathrm{CH}_{4} / \mathrm{EB}$ is the percentage share of gross energy loss in methane and $\mathrm{dE}$ is a digestibility index, for each feedstuff. The digestibility index is taken from Kalaisakis (1965). Furthermore, the following equation proposed by Vermorel et al. (2008) is used for the estimation of methane emissions from grass consumed by grazing sheep:

$$
Y^{\prime} m=-0.150 d E+21.89
$$

where $\mathrm{Y}_{\mathrm{m}}^{\prime}$ refers to methane (in kcal) per $100 \mathrm{kcal}$ of metabolisable energy. Methane produced from livestock excreta is considered negligible, since no anaerobic conditions exist during the management of manure or grazing of sheep (IPCC 2006; Petersen et al. 2009). On the other hand, when aerobic conditions exist, $\mathrm{N}_{2} \mathrm{O}$ is produced, and, therefore, direct and indirect $\mathrm{N}_{2} \mathrm{O}$ emissions from livestock excreta, deposited on pastureland and managed in piles, are included in the analysis. These emissions are estimated according to the Tier 1 methodology, proposed by the IPCC (2006).

In our analysis, we have included direct and indirect $\mathrm{N}_{2} \mathrm{O}$ emissions from the use of nitrogen fertilisers. First, the total amount of nitrogen applied in fields has been calculated using the amount and the type of fertiliser (De Cara and Jayet 2000; Petersen et al. 2009). Then, direct, indirect and leaching emissions from the applied $\mathrm{N}$ have been estimated according to the tier 1 methodology and the emission factors proposed by the IPCC (2006). Pre-chain emissions have also been estimated and included in the analysis, following the work of Olesen et al. (2006). As mentioned above, farmers choose whether to feed their flock with on- or off-farm-produced crops. Therefore, emissions from the nitrogen fertilisers used for the off-farm production of feedstuffs have also been estimated and incorporated in the model. Specifically, $\mathrm{N}_{2} \mathrm{O}$ emissions from purchased alfalfa and maize have been estimated using data gathered from 85 and 73 farmers of the area, respectively.

Carbon dioxide from energy use is another source of GHG emissions in crop-livestock farms. The main sources of energy in these farms are fuel (mainly diesel) and electricity (see also Olesen et al. 2006). To estimate the emissions from energy use, fuel or electricity requirements for every operation and type of machinery are estimated and multiplied by emission factors (Petersen et al. 2009). As in the case of $\mathrm{N}_{2} \mathrm{O}, \mathrm{CO}_{2}$ emissions from energy requirements of purchased feed are also estimated, according to the data gathered from the farmers of the area. Other inputs like fertilisers and pesticides used in both produced and purchased crops have also caused GHG emissions when they were manufactured. These emissions have been taken into account as well, using farm-level data to estimate the amount of inputs used and related literature to estimate the emissions caused by the manufacture of these inputs. Carbon dioxide emissions from the manufacture of fertilisers are taken from Wood and Cowie (2004), and emissions from the manufacture of pesticides are taken from Audsley et al. (2009). 
Sheep farming also has a positive impact as far as GHG emissions are concerned, since crops and pastureland are responsible for carbon sequestration. We have assumed a carbon sequestration of $110 \mathrm{~kg}$ of $\mathrm{CO}_{2}$ equivalents per stremma ${ }^{3}$ for crops $(0.3 \mathrm{tC} / \mathrm{ha})$ and $60 \mathrm{~kg}$ of $\mathrm{CO}_{2}$ equivalents per stremma for pastureland $(0.16 \mathrm{tC} / \mathrm{ha})$ (see also Pretty and Ball 2001). These sequestration estimations are subtracted from the total emitted GHGs estimated above so that net emissions can be assessed.

\subsection{Data}

The analysis is undertaken in two sheep farms that represent the extensive and the semi-intensive farming systems and are located in lowland areas of the prefecture of Etoloakarnania, in Western Greece. More specifically, the semi-intensive farm has a flock size of 315 ewes with an annual production of milk about $190 \mathrm{~kg} / \mathrm{ewe}$. The live weight of the ewe is $60 \mathrm{~kg}$, and the prolificacy index is $1.5 \mathrm{lambs} / \mathrm{ewe}$. The semiintensive farm maintains $70 \mathrm{strm}$ of alfalfa and $30 \mathrm{strm}$ of maize for feeding of the flock and utilises $500 \mathrm{strm}$ of pastureland. The milking period is prolonged (from November to July) since there are two lambing periods, in late September and February.

The extensive farm has a flock size of 160 ewes and an annual production of milk of about $100 \mathrm{~kg} / \mathrm{ewe}$. The live weight of the ewes and the prolificacy index are also lower in the extensive farm (50 kg/ewe and 1.3 lambs/ewe, respectively). In the farm, $20 \mathrm{strm}$ of alfalfa and $18 \mathrm{strm}$ of maize are cultivated, but the feeding requirements are mainly met through grazing ( $800 \mathrm{strm}$ of pastureland). Labour inputs are offered mainly by the farmer, and the milking period is smaller than in the case of the semi-intensive farm (January to May). Detailed data from the two farms is used to derive all technical and economic coefficients of the model.

\subsection{Application and Results}

The mathematical programming model is used to simulate the operation of the two farms, and the optimal farm plan is obtained. This optimal farm plan is used to evaluate the performance of the farms, which is discussed in detail in the following paragraphs. ${ }^{4}$ The constraint on net emissions is then inserted, and the optimal farm plan is again obtained for various levels of abatement, through parametric optimisation. This way, the best abatement strategy for each farm can be identified. Finally, the marginal abatement cost for each of the farms is estimated and the marginal abatement cost curve is built.

\footnotetext{
${ }^{3} 1$ stremma $(\mathrm{strm})=0.1$ ha.

${ }^{4}$ It should be noted that the performance of the mathematical model is satisfactory, since the optimal farm plan is very close to the observed one, especially in the case of the semi-intensive farm.
} 


\subsubsection{Socio-economic Performance}

Table 15.1 contains the optimal farm plan for the semi-intensive farm. The total gross margin and the gross margin per ewe are 56,775 € and $179 €$, respectively. According to Kitsopanides (2006), semi-intensive farms are considered profitable and have an annual net return of $29.4 €$ /ewe. Although the model used in this analysis maximises gross margin, fixed cost is known and can be used to evaluate net return, which is $45.2 € /$ ewe, indicating that the economic performance of the semi-intensive farm is very satisfactory. As far as the employment level is concerned, the farm offers full-time employment to the two owners, since family labour is $3,463 \mathrm{~h}$ and extra hired labour is also required $(87 \mathrm{~h})$.

On the other hand, the extensive farm has a lower gross margin per productive ewe (117 €) (Table 15.2). According to Kitsopanides (2006), extensive farms have a negative net return $(-5.6 € /$ ewe). In this analysis, the net return of the extensive farm is small but positive ( $6.4 €$ /ewe), indicating that the activity is viable. Labour inputs per ewe are higher compared to the semi-intensive farm due to the extra labour required for grazing and to the limited invested capital (e.g. absence of milking machine).

The environmental performance of the two farms is discussed in detail in the next paragraph. Tables 15.1 and 15.2, however, contain the optimal farm plan for the farms under the hypothesis of various levels of abatement, or in other words the optimal abatement strategy for the farms. A $10 \%$ abatement for the semi-intensive farm leads to a $5 \%$ reduction of the gross margin and an $11 \%$ reduction of labour (Table 15.1). At a $20 \%$ abatement level, the reduction in gross margin and labour is $10 \%$ and $22 \%$, respectively, and full-time employment is offered to only one of the owners. The overall reduction of gross margin is 5,729 €, and the average abatement cost is $18 €$ /ewe, which can be used as an indication of the compensation/ewe the farmer should receive for abating.

In the case of the extensive farm, 10\% abatement causes a trivial (less than 1\%) reduction of the gross margin (Table 15.2). The reason for this is that the gross margin generated by the sheep farming activity is, in the case of the extensive farm, very small compared to the semi-intensive farm, mainly due to low productivity. Thus, the income loss can easily be replaced by the income generated from cash crop production. The substitution of the sheep farming activity with cash crops is evident in both production systems. The difference is that only in the case of the extensive farming system can this substitution compensate for the income lost from the restriction of the sheep farming activity. Table 15.2 also indicates that $20 \%$ abatement causes only a $5 \%$ reduction on the gross margin of the farm. On the other hand, abatement has a significant impact on the employment level of the extensive farm as well, since sheep farming, which has high labour requirements, is gradually abandoned. Specifically, $10 \%$ and $20 \%$ abatement cause $10 \%$ and $17 \%$ reduction in labour, respectively. 


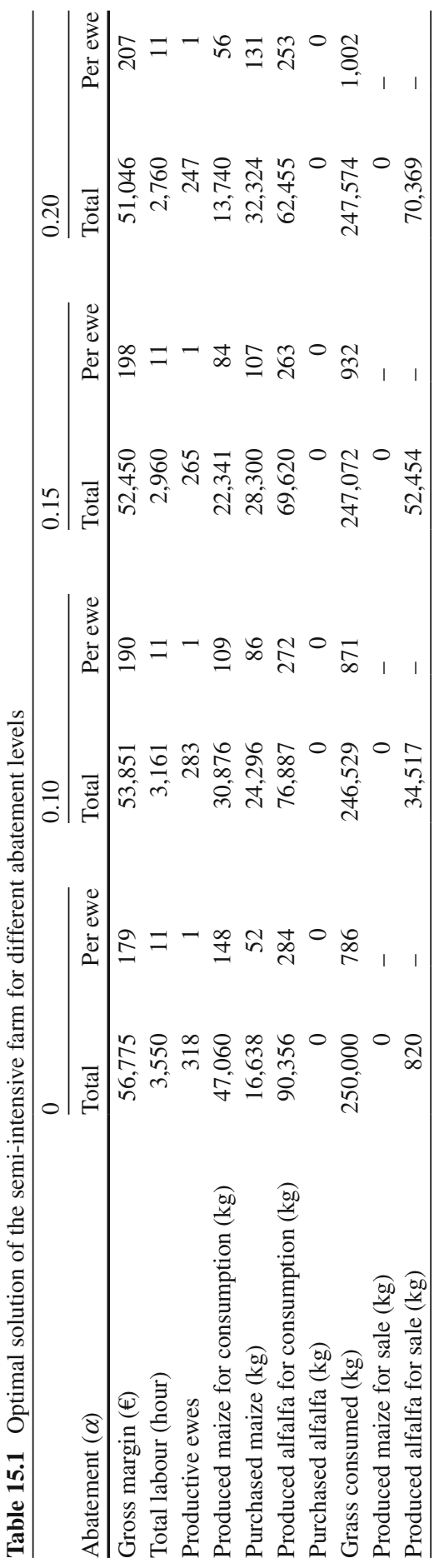




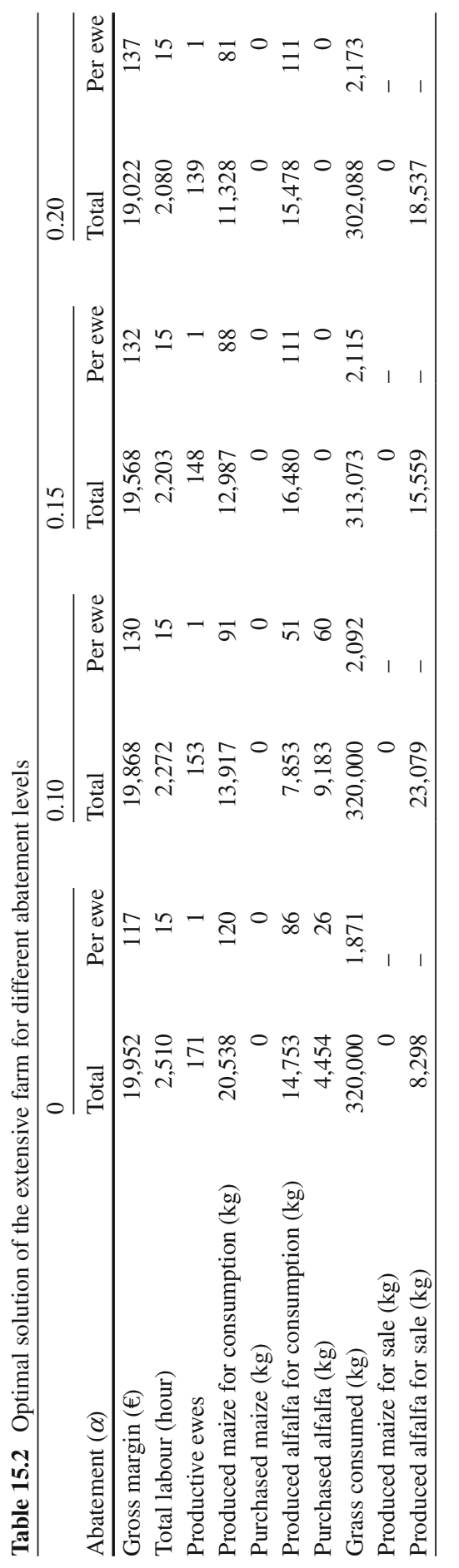




\subsubsection{Environmental Performance}

The environmental performance of the semi-intensive farm and the extensive farm and specifically their GHG emissions are presented in Tables 15.3 and 15.4. Specifically, Tables 15.3 and 15.4 contain the overall emissions of the farms as well as the emissions per main source.

The net emissions (total emissions minus carbon sequestration) are also presented. The main source of GHGs in sheep farms is enteric fermentation, since it is responsible for $71 \%$ of the total emitted GHGs of the semi-intensive farm and $78 \%$ of the total emitted GHGs of the extensive farm. Similar findings on the contribution of $\mathrm{CH}_{4}$ emissions in ruminant livestock farms have been reported in previous studies (e.g. Smith and Upadhyay 2005; Petersen et al. 2009). Twenty-one per cent of the emissions of the semi-intensive farm refer to $\mathrm{N}_{2} \mathrm{O}$ emissions, and the remaining $8 \%$ are $\mathrm{CO}_{2}$ emissions (Table 15.3). As far as the extensive farm is concerned, $\mathrm{N}_{2} \mathrm{O}$ is responsible for $16 \%$ of the total emitted GHGs, and $\mathrm{CO}_{2}$ accounts for only $6 \%$ of the total emitted GHGs (Table 15.4). Emissions from enteric fermentation per $\mathrm{kg}$ of milk are higher in the case of the extensive farm because of the higher participation of primarily grass and secondarily alfalfa in livestock feeding.

Net emissions of the semi-intensive farm are about $180 \mathrm{t}$ or $2.99 \mathrm{~kg}$ of $\mathrm{CO}_{2}$ equivalents/ $\mathrm{kg}$ of milk. For the extensive farm, net emissions are significantly higher, reaching $5.45 \mathrm{~kg}$ of $\mathrm{CO}_{2}$ equivalents/kg of milk (net emissions are over $93 \mathrm{t}$ ). Tables 15.3 and 15.4 also contain emissions by source, at various levels of abatement. Abatement is in both production systems accompanied by a switch towards cash crops production and, specifically, alfalfa production. This is because alfalfa requires less fertiliser inputs and therefore causes fewer emissions. Furthermore, alfalfa generates a high gross margin, since it has a high yield. The substitution of the sheep farming activity with crop activities has also been pointed out in the study of Petersen et al. (2009) on GHG abatement in extensive grazing systems of south-western Australia. As can be observed in Table 15.3, abatement in semi-intensive farms is achieved by reducing $\mathrm{CH}_{4}$ emissions from enteric fermentation and $\mathrm{N}_{2} \mathrm{O}$ emissions from livestock and maize production.

Specifically, in order to achieve a $10 \%$ abatement of net emissions in the semiintensive farm, $\mathrm{CH}_{4}$ emissions are reduced by $9 \%$. This reduction is achieved by the reduction of the number of ewes by 35 . The analysis indicates, however, that the semi-intensive farms continue to utilise their pastureland, even though grass consumption causes $\mathrm{CH}_{4}$ emissions. This is probably because in our analysis, carbon sequestration of pastureland is also taken under consideration. Similarly, a $20 \%$ reduction of net emissions leads to an $18 \%$ reduction of $\mathrm{CH}_{4}$ and a $45 \%$ reduction in $\mathrm{N}_{2} \mathrm{O}$ emissions from crops. Abatement is again achieved through the reduction of the number of ewes and a switch towards cash crops. It should also be mentioned that as the level of abatement increases, semi-intensive farms rely more on concentrates (maize) for the feeding of the flock, since less alfalfa is used in the ration.

In the case of the extensive farm, abatement is again achieved through change in production orientation from sheep to cash crops (Table 15.4). As mentioned above, 


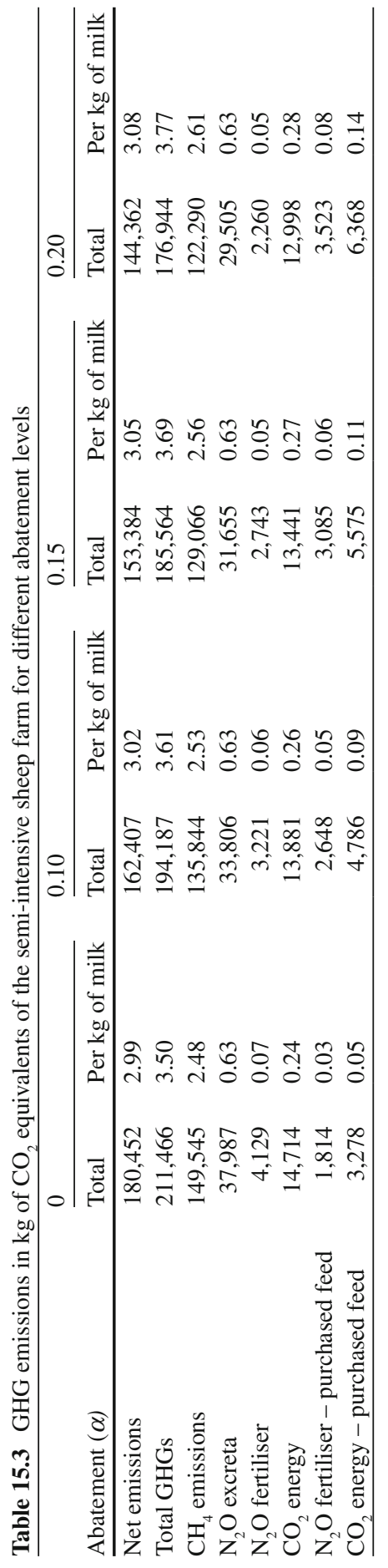




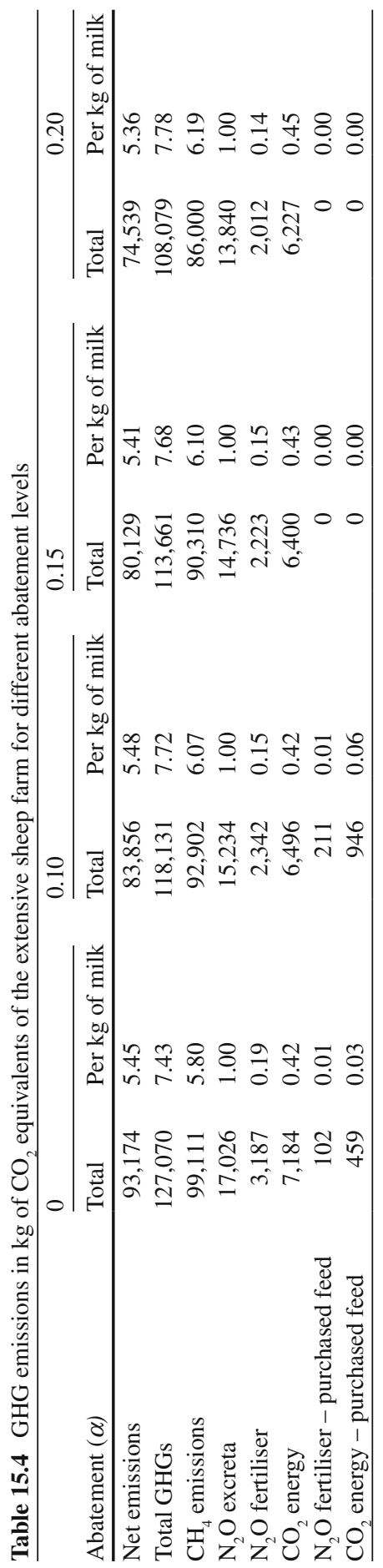


Fig. 15.1 Marginal abatement cost of the semi-intensive farm for different abatement levels

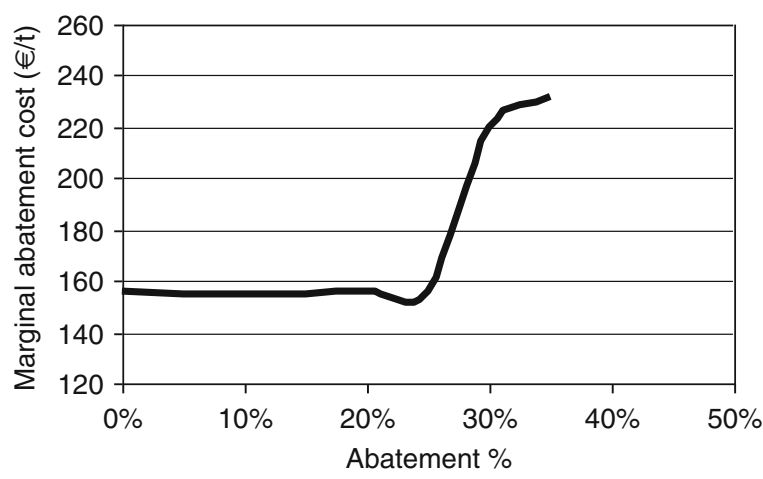

this substitution minimises the impact of abatement in extensive farms, due to the low gross margin of sheep farming and the high yield of alfalfa. In the case of the extensive farm, $\mathrm{CH}_{4}$ emissions from enteric fermentation are reduced only by $6 \%$ and $13 \%$ in order to achieve $10 \%$ and $20 \%$ abatement, respectively. This reduction of $\mathrm{CH}_{4}$ emissions is achieved only by reducing the flock size and not by increasing the proportion of concentrates used in the ration.

\subsubsection{Abatement Cost}

Figure 15.1 presents the abatement cost curve for the semi-intensive farm. As can be seen in this figure, the curve indicates an increasing marginal abatement cost. This marginal abatement cost is $156 € / t$ until $25 \%$ abatement is achieved. Then the abatement cost increases to reach $220 € / t$ and $232 € / t$, at $30 \%$ and $35 \%$ abatement, respectively. These findings denote the significant impact that abatement has on the gross margin of semi-intensive farms, since the income generated by crop production cannot replace the income lost from the restriction of the sheep farming activity.

The abatement cost curve of the extensive farm is presented in Fig. 15.2. As in the case of the semi-intensive farm, the marginal abatement cost of the extensive farm is also increasing, with an average of $50 € / \mathrm{t}$, until a $20 \%$ abatement is reached. The shadow price of net emissions is very small at current emission levels $(5 € / t)$ and gradually increases to $10 € / \mathrm{t}$ at $10 \%$ abatement, $91 € / \mathrm{t}$ at $20 \%$ abatement, 154 $€ / \mathrm{t}$ at $25 \%$ abatement and $218 € / \mathrm{t}$ at $50 \%$ abatement.

Breen and Donnellan (2009) estimated a marginal abatement cost of 110-230 €/t for dairy farms in Ireland, while De Cara and Jayet (2000) estimated the marginal cost, that varied significantly amongst farm types, from 30 to $300 € /$ t. The low abatement cost of the extensive farm, until $25 \%$ abatement is achieved, is explained by the substitution of sheep farming with almost equally profitable crop activities. These results support the heterogeneity of the marginal abatement cost within the sheep farming activity in Greece. The heterogeneity of the GHG abatement cost has been pointed out in a number of studies (e.g. De Cara and Jayet 2000). 
Fig. 15.2 Marginal abatement cost of the extensive farm for different abatement levels

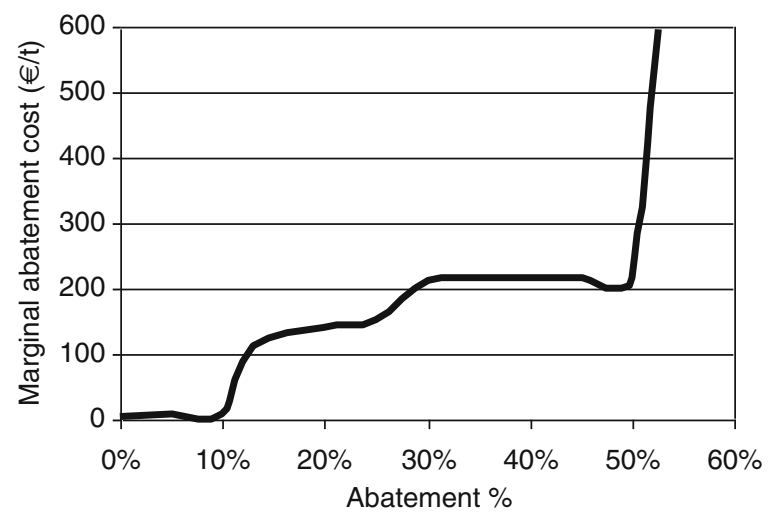

Assessing the marginal abatement cost is useful to policymakers who wish to develop well-targeted and well-designed abatement policy measures. One potential policy measure is the implementation of a tax per ton of emitted $\mathrm{CO}_{2}$ equivalents (Neufeldt and Schäfer 2008; Petersen et al. 2009). The analysis can assist in the determination of the level of this tax according to the abatement cost of the farms (see also De Cara and Jayet 2000). If a tax smaller than the marginal abatement cost of a farm is implemented, then the farmer will choose to pay the implemented tax instead of abating, and, thus, the policy measure will be ineffective. For example, according to our analysis, a tax of $90 € / t$ of $\mathrm{CO}_{2}$ equivalents will have no effect on the emissions of the semi-intensive farms but will succeed to reduce emissions of the extensive farm up to $20 \%$. Furthermore, this tax will also have an impact on the sustainability of the extensive farming system since it can lead to the restriction of the sheep farming activity.

\subsection{Concluding Remarks}

In this study, a mathematical programming model was used to derive the optimal farm plan of sheep farms and estimate their socio-economic and environmental (in terms of GHG emissions) performance. The abatement strategy and the marginal abatement cost of sheep farms are also estimated. The analysis is undertaken in two sheep farms that represent the semi-intensive and the extensive production systems and includes pre-chain emissions as well as all potential emission sources in the farm. The model maximises gross margin that is used as an economic sustainability indicator. Labour inputs are used as a social performance indicator and GHG emissions as an environmental sustainability indicator.

The results of the analysis indicate that both production systems are economically viable, though the semi-intensive farm has a higher gross margin than the extensive one. The main source of GHG emissions in dairy sheep farms is enteric 
fermentation. Emissions are particularly high in extensive farms, because of the excessive use of grass and alfalfa for feed. Thus, the semi-intensive system is more efficient in socio-economic but also environmental terms. Across various abatement levels, the optimal solution indicates that abatement is achieved in both production systems, via a switch to cash crops. This has a significant impact only on the gross margin of the semi-intensive farms that are characterised by high productivity. On the other hand, abatement has a significant impact on employment, since the labour requirements of crop production are significantly lower than the labour requirements of sheep farming. As far as the marginal abatement cost is concerned, it is increasing across various levels of abatement, and it is significantly higher in the case of the semi-intensive farm.

The results of the analysis of the two farms are an indication of the heterogeneity of the abatement cost amongst sheep farms with different characteristics. Utilising a farm typology can reflect this heterogeneity more accurately and can be used to estimate the total cost of abating for the country. However, the results of the analysis have highlighted some aspects of the sustainability of the sheep farming activity and can be used as a guide for the development of effective mitigation policy measures.

Acknowledgements This research has been co-financed by the European Union (European Social Fund - ESF) and Greek national funds through the Operational Programme "Education and Lifelong Learning" of the National Strategic Reference Framework (NSRF) - Research Funding Program: Heracleitus II - investing in knowledge society through the European Social Fund.

\section{References}

Alford, A. R., Griffith, G. R., Cacho, O. (2004, March). A Northern Tablelands whole-farm linear program for economic evaluation of new technologies at the farm-level. (Economic Research Report No. 13), Retrieved from NSW Website: http://www.dpi.nsw.gov.au/research/areas/biosecurity/economics-research/reports/err13

Audsley, E., Stacey, K., Parson, D. J., Williams, A. G. (2009). Estimation of the greenhouse gas emissions from agricultural pesticide manufacture and use. Retrieved December 1, 2009, from Cranfield University. Prepared for Crop Protection Association. Web site: https://dspace.lib. cranfield.ac.uk/bitstream/1826/3913/1/Estimation_of_the_greenhouse_gas_emissions_from_ agricultural_pesticide_manufacture_and_use-2009.pdf

Benoit, M., \& Laignel, G. (2008, July). Sheep for meat farming systems in French semi-upland area. Adapting to new context: increased concentrates and energy prices, and new agricultural policy (Paper presented at the 8th Symposium of the International Farming Systems, ClermontFerrand, France).

Breen, J., Donnellan, T. (2009, March-April). Estimating the marginal cost of greenhouse gas emissions abatement using Irish farm-level data. (Paper presented at the 83rd Annual Conference of the Agricultural Economics Society, Dublin, Ireland).

Crosson, P., O' Kiely, P., O’ Mara, F. P., \& Wallace, M. (2006). The development of a mathematical model to investigate Irish beef production systems. Agricultural System, 89, 349-370.

De Cara, S., \& Jayet, P. A. (2000). Emissions of greenhouse gases from agriculture: The heterogeneity of abatement costs in France. European Review of Agricultural Economics, 27(3), 281-303.

H.M.R.D.F. (2007). Sheep and Goat Sector Development. Retrieved October 17, 2007 from: http:// www.minagric.gr/greek/ENHM_FYLADIA_ZWIKHS/ENHM_FYL_zoiki.htm (in Greek). 
IPCC. (2006). IPCC Guidelines for national greenhouse gas inventories. Retrieved March 6, 2010 from Intergovernmental Panel on Climate Change: Bracknell, U.K. Web site: http://www. ipcc-nggip.iges.or.jp/public/2006gl/vol4.html

Kalaisakis, P. (1965). Applied animal nutrition. Athens: Giourdas M. Publishing. in Greek.

Kitsopanides, G. (2006). Economics of animal production. Thessaloniki: ZITI Publishing. in Greek.

Neufeldt, H., \& Schäfer, M. (2008). Mitigation strategies for greenhouse gas emissions from agriculture using a regional economic-ecosystem model. Agriculture, Ecosystems \& Environment, $123,305-314$.

Olesen, J. E., Schelde, K., Weiske, A., Weisbjerg, M. R., Asman, W. A. H., \& Djurhuus, J. (2006). Modelling greenhouse gas emissions from European conventional and organic dairy farms. Agriculture, Ecosystems \& Environment, 112, 207-220.

Petersen, E. H., Schilizzi, S., Bennet, D. (2009). The impacts of greenhouse gas abatement policies on the predominantly grazing systems of south-western Australia. Retrieved October 2, 2009 from the Australian National University, Asia Pacific School of Economics and Government, International and development Economics: Working Paper 02-9 Web site: http://www.crawford.anu.edu.au/degrees/idec/working_papers/IDEC02-9.pdf

Pitesky, M., Stachhouse, K. R., \& Mitloehner, F. M. (2009). Clearing the air: Livestock's contribution to climate change. Advances in Agronomy, 103, 1-40.

Pretty, J., \& Ball, A. (2001). Agricultural influences on carbon sequestration: A review of evidence and the emerging trading options. Retrieved October 2, 2009, from the University of Essex, Center for Environment and Society and Department of Biological Studies, Occasional Paper 2001-2003, Website: http://citeseerx.ist.psu.edu/viewdoc/download?doi=10.1.1.188.7509\&re $\mathrm{p}=\mathrm{rep} 1 \&$ type $=\mathrm{pdf}$

Schils, R. L. M., de Haan, M. H. A., Hemmer, J. G. A., van den Pol-van Dasselaar, A., de Boer, J. A., Evers, A. G., Holshof, G., van Middelkoop, J. C., \& Zom, R. L. G. (2007). DairyWise, a whole-farm dairy model. American Dairy Science Association, 90, 5334-5346.

Smith, E. G., \& Upadhyay, M. (2005, July). Greenhouse gas mitigation on diversified farms. (Paper presented at the Western Agricultural economics Association-Western Economics Association International Joint Annual Meeting, San Francisco, CA, USA).

Vermorel, M., Jouany, J.-P., Eugene, M., Sauvant, D., Noblet, J., \& Dourmad, J.-Y. (2008). Evaluation quantitative des émissions de méthane entérique par les animaux d'élevage en 2007 en France. INRA Productions Animales, 21(5), 403-418.

Veysset, P., Bedin, D., \& Lherm, M. (2005). Adaptation to Agenda 2000 (CAP reform) and optimization of the farming system of French suckler cattle farms in the Charolais area: A modelbased study. Agricultural Systems, 83, 179-202.

Veysset, P., Lherm, M., \& Bédin, D. (2010). Energy consumption, greenhouse gas emissions and economic performance assessments in French Charolais suckler cattle farms: Model-based analysis and forecasts. Agricultural Systems, 103, 41-50.

Weiske, A., Vabitsch, A., Olesen, J. E., Schelde, K., Michel, J., Friedrich, R., \& Kaltschmitt, M. (2006). Mitigation of greenhouse gas emissions in European conventional and organic dairy farming. Agriculture, Ecosystems \& Environment, 112, 221-232.

Wood, S., \& Cowie, A. (2004, July). A review of greenhouse gas emission factors for fertilizer production. IEA Bioenergy Task 38. Retrieved from http://www.ieabioenergy-task38.org/ publications/GHG_Emission_Fertilizer\%20Production_July2004.pdf

Zervas, G., Kalaisakis, P., \& Feggeros, K. (2000). Farm animal nutrition. Athens: Stamoulis Publishing. n Greek. 